\title{
Platelet-derived growth factor receptor- $\beta$ and epidermal growth factor receptor in pulmonary vasculature of systemic sclerosis-associated pulmonary arterial hypertension versus idiopathic pulmonary arterial hypertension and pulmonary veno-occlusive disease: a case-control study
}

\author{
Maria J Overbeek ${ }^{1 *}$, Anco Boonstra $^{1}$, Alexandre E Voskuyl2 ${ }^{2}$, Madelon C Vonk ${ }^{3}$, Anton Vonk-Noordegraaf ${ }^{1}$,
} Maria PA van Berkel ${ }^{4}$, Wolter J Mooi ${ }^{5}$, Ben AC Dijkmans ${ }^{2}$, Laurens S Hondema ${ }^{5}$, Egbert F Smit ${ }^{1}$ and Katrien Grünberg ${ }^{5}$

\begin{abstract}
Introduction: Systemic sclerosis (SSc) complicated by pulmonary arterial hypertension (PAH) carries a poor prognosis, despite pulmonary vascular dilating therapy. Platelet-derived growth factor receptor- $\beta$ (PDGFR- $\beta$ ) and epidermal growth factor receptor (EGFR) are potential therapeutic targets for PAH because of their proliferative effects on vessel remodelling. To explore their role in SSCPAH, we compared PDGFR- and EGFR-mmunoreactivity in lung tissue specimens from SSCPAH. We compared staining patterns with idiopathic PAH (IPAH) and pulmonary veno-occlusive disease (PVOD), as SSCPAH vasculopathy differs from IPAH and sometimes displays features of PVOD. Immunoreactivity patterns of phosphorylated PDGFR- $\beta$ (pPDGFR- $\beta$ ) and the ligand PDGF-B were evaluated to provide more insight into the patterns of PDGFR-b activation.
\end{abstract}

Methods: Lung tissue specimens from five SSCPAH, nine IPAH, six PVOD patients and five controls were examined. Immunoreactivity was scored for presence, distribution and intensity.

Results: All SSCPAH and three of nine IPAH cases $(P=0.03)$ showed PDGFR- $\beta$-immunoreactivity in small vessels (arterioles/venules); of five SSCPAH vs. two of nine IPAH cases $(P=0.02)$ showed venous immunoreactivity. In small vessels, intensity was stronger in SSCPAH vs. IPAH. No differences were found between SSCPAH and PVOD. One of five normal controls demonstrated focally mild immunoreactivity. There were no differences in PDGF-ligand and PPDGFR-b-immunoreactivity between patient groups; however, PPDGFR-b-immunoreactivity tended to be more prevalent in SSCPAH small vasculature compared to IPAH. Vascular EGFR-immunoreactivity was limited to arterial and arteriolar walls, without differences between groups. No immunoreactivity was observed in vasculature of normals.

Conclusions: PDGFR- $\beta$-immunoreactivity in SSCPAH is more common and intense in small- and post-capillary vessels than in IPAH and does not differ from PVOD, fitting in with histomorphological distribution of vasculopathy. PDGFR- $\beta$ immunoreactivity pattern is not paralleled by pPDGFR- $\beta$ or PDGF-B patterns. PDGFR- $\beta$ - and EGFRimmunoreactivity of pulmonary vessels distinguishes PAH patients from controls.

\footnotetext{
* Correspondence: mj.overbeek@vumc.nl

'Department of Pulmonary Diseases, VU University Medical Center, De

Boelelaan 1117, $1081 \mathrm{HV}$, Amsterdam, The Netherlands

Full list of author information is available at the end of the article
} 


\section{Introduction}

Systemic sclerosis (SSc) is an autoimmune disease characterized by dysfunction of endothelium, an altered immune tolerance and the deposition of excessive amounts of extra-cellular matrix components in multiple organ systems (reviewed by Gabrielli in [1]). Pulmonary involvement, either lung fibrosis or pulmonary arterial hypertension (PAH), is the leading cause of death in SSc [2]. Patients with SSc are at high risk of developing $\mathrm{PAH}$, with estimated prevalences ranging from 7.9 to $12 \%[3,4]$. SScPAH carries a poor prognosis with three-year patient survival rates of 47 to $56 \%$ despite therapy [5-8], although survival has improved when compared with historical series. Still, these survival rates are worse compared to, for example, idiopathic PAH (IPAH). In SScPAH, the clinical benefit from current $\mathrm{PAH}$ therapies also compares unfavourably to that of IPAH [9-11], although some have been reported effective $[12,13]$. SScPAH also differs from IPAH with respect to pulmonary and hemodynamic function [14-17]. Notably, SScPAH typically has lower right ventricular- and pulmonary artery pressures as well as diffusion capacity of the lung for carbon monoxide $[6,14,15,17,18]$. Pulmonary vasculopathy in SScPAH differs qualitatively from that of IPAH and resembles pulmonary veno-occlusive disease (PVOD), a rare form of $\mathrm{PAH}$, in some instances $[19,20]$. It seems reasonable to assume that the clinical and histomorphologic differences point to quantitative or even qualitative differences in pathogenetic mechanisms of pulmonary vascular lesions in SScPAH and IPAH.

Growth factor receptors, such as platelet-derived growth factor receptor (PDGFR- $\beta$ ) and epidermal growth factor receptor (EGFR), have been implicated in the pathogenesis of SSc. SSc skin and cultured fibroblasts demonstrate enhanced protein expression of PDGFR- $\beta$, and in SSc patients with progressive disease, increased PDGFR- $\beta$-plasma levels have been found [21-25]. Imatinib, a dual inhibitor of the tyrosine kinase c-Abl and PDGFR, has been shown to inhibit progression and to induce regression of fibrosis in vivo [26]. In addition, increased expression of EGFR in fibroblasts from patients with SSc has been shown $[27,28]$. Indirect relations with the EGFR signaling system and TGF-b, an important pro-fibrotic mediator in SSc, have been described [27]. In pulmonary hypertension, a role of PDGFR- $\beta$ and EGFR in the improvement of hemodynamic function has been suggested in animal models [29-31]. It is noteworthy in this context that PDGFR- $\beta$ plays a role in activation of EGFR [32]. In IPAH patients, increased and activated PDGFR- $\beta$ has been demonstrated in pulmonary arteries [33]. Moreover, there is anecdotal evidence that inhibition of PDGFR- $\beta$ is effective in patients with IPAH and in patients with
PVOD [34-37]. The role of PDGFR- $\beta$ and EGFR in $\mathrm{SScPAH}$, however, is as yet unclear.

Here, we examined the presence, localization and intensity of immunostaining for PDGFR- $\beta$ and EGFR in the pulmonary vasculature of SScPAH, and compared these with IPAH, PVOD, and normal controls. Phosphorylated (p) PDGFR- $\beta$ and PDGF-B immunoractivity was evaluated to give more insight in activation patterns of PDGFR- $\beta$.

\section{Materials and methods \\ Patients}

The diagnosis of SScPAH, IPAH and PVOD was verified by reviewing the medical records. Only patients diagnosed with PAH upon right heart catheterization, with a mean resting pulmonary arterial pressure $(\mathrm{mPpa}) \geq 25$ $\mathrm{mmHg}$ and a pulmonary capillary wedge pressure $\leq 15$ $\mathrm{mmHg}$, were included. The diagnosis of SSc was established by a rheumatologist. SSc patients had to fulfil the preliminary ACR classification criteria for SSc and were classified according to LeRoy et al. [38,39]. Patients with restrictive disease as indicated by total lung capacity as a percentage of predicted (TLC\%) $<70 \%$, vital capacity (VC\%) $<70 \%$ and/or severe fibrosis on HRCT scan were excluded. Lung tissue from five subjects who had died from extra-pulmonary trauma and who had no cardiorespiratory medical history, was used as a control. Histopathological diagnosis of pulmonary vascular disease was confirmed by independent reading by two pathologists (WJM, KG). PVOD was diagnosed based on the presence of a picture of patchy intense capillary congestion in the alveolar parenchyma, and obliterative intimal, loosely textured fibrosis of small veins and venules. PVOD cases did not have arterialised interlobular veins: this is indicative of congestive vasculopathy $[40,41]$.

The cases were collected from the Departments of Pulmonary Diseases and Rheumatology of the VU University Medical Center, Amsterdam and from the Department of Rheumatology of the Radboud University Nijmegen Medical Center, Nijmegen, both in The Netherlands. The study, including the use of archived tissue was approved by the Institutional Review Board on Research Involving Human Subjects of the VU University Medical Center.

\section{Tissue preparation and immunohistochemistry}

Immunohistochemistry was performed on formalin-fixed paraffin-embedded $4 \mu \mathrm{m}$ sections of lung tissue. All sections were stained in one batch for each marker. Antibodies against PDGFR- $\beta$ (Cell Signaling Technology, Danvers, MA, USA) and pPDGFR- $\beta$ (Novus Biologicals, Littleton, CO, USA) were used at dilutions of 1:50 and 1:150, respectively. Active PDGF is built up by polypeptides that form hetero- and homodimers. An antibody 
specific for the PDGF-B form (Novus Biologicals) was used; it reacts with the PDGF (AB) and PDGF (BB) protein. The dilution used for this antibody was 1:400. For EGFR staining, a monoclonal antibody against EGFR (Novocastra, Newcastle upon Tyne, UK) was used. Immunostaining for the constitutively expressed endothelial marker CD31 (PECAM-1, clone JC70a, Dako, Glostrup, Denmark) served as a reference for the exact localization of PDGFR-b and EGFR staining, as well as for PDGFR-b- and EGFR staining intensity, as staining intensity might be influenced by age of the blocks and duration of fixation. Isotype-matched control-staining was performed with rabbit anti-FITC IgG (Invitrogen, Camarillo, CA, USA). Additional detail on immunostaining is provided in an online data supplement (Additional file 1; figures of isotype-matched control staining: Additional file 2).

\section{Scoring}

Intensity of immunoreactivity was scored semi-quantitatively as absent, mild, moderate and strong on a 0 to 3 point scale. Immunoreactivity was assessed in pulmonary arteries, arterioles, capillaries, venules and veins, and, where applicable, in intima, media and adventitia. Arteries were identified by their accompanying bronchiole and the presence of a lamina elastica interna and externa. Vessels were identified as arteriole when their parent artery could be identified. In case arterioles or venules could not be distinguished by their anatomical localisation, they were collectively designated as "small vessels". Veins were identified in case they were located in interlobular septa, and venules in case they could be anatomically deduced from a draining vein. Intimal fibrosis was recognizable by Elastica von Gieson-stained slides.

The overall distribution of immunoreactivity in vessels was scored as focal, multifocal or widespread, with reference to the type of vessel and micro-anatomical localization. In case of pPDGF- $\beta$ and PDGF-B, positively stained cells were assessed as 0 to $25 \%, 25$ to $50 \%, 50$ to $75 \%$ and $>75 \%$. Staining was designated as focal if $25 \%$, multifocal if 25 to $75 \%$ and widespread if more than $75 \%$ of the cells were positively stained. Scoring took place by two independent readers (KG, MJO) blinded to the clinical diagnoses. Discrepant scores were reviewed to reach consensus. In none of the cases was there disagreement.

\section{Statistics}

SPSS 12.0 software package (Chicago, IL, USA) was used for statistical analyses. The Kruskal-Wallis test was used for comparison of means concerning demographic-, pulmonary function- and hemodynamic parameters. For the comparison of the presence and of the intensity of immunoreactivity, Fisher's Exact test was used to compare non-parametric data between groups. A $P$-value < 0.05 was considered statistically significant. Other parameters were analysed descriptively due to lack of statistical power.

\section{Results}

Lung tissue samples from five SScPAH, nine IPAH, six PVOD patients and five controls were collected. Samples had been obtained at autopsy $(n=17)$, open lung biopsy ( $n=5$; one SScPAH patient, four PVOD patients) or at lung explantation $(n=3$; one SScPAH, one IPAH and one PVOD patient). Patient characteristics are shown in Table 1. The SSc patients were classified as having the limited cutaneous form of the disease [40]. The groups did not differ significantly with respect to mean age. None of the patients outside the SSc group had been diagnosed with systemic sclerosis. The hemodynamic parameters, listed in Table 2, were not significantly different between the SScPAH, IPAH and PVOD groups. CD31 staining intensity varied only marginally among cases.

\section{PDGFR- $\beta$ immunoreactivity}

In SScPAH, PDGFR- $\beta$ immunoreactivity was present in the complete spectrum of the pulmonary vasculature, in vessels both with and without intimal fibrosis. PDGFR- $\beta$ was expressed focally in the adventitia and media of axial arteries and arterioles. In the intimal layer of the small vessels, all SScPAH patients demonstrated, albeit focally, immunoreactivity (Figure 1A, B). In the capillaries, PDGFR- $\beta$ immunoreactivity was widespread in each of the five SScPAH patients (Figure 1A, B, D). This immunoreactivity was present in areas with and without congestion. At venular-venous level, in four out of five SScPAH patients a mild, focal PDGFR- $\beta$ immunoreactivity was observed in the intima (Figure $1 \mathrm{~F}$ ).

In IPAH, PDGFR- $\beta$ immunoreactivity of the intimal and adventitial layers of the arteries and the arterioles was focally observed (Figure 1G). Only three out of nine IPAH patients revealed a focal immunoreactivity of the intima in small vessels. The prevalence was significantly lower as compared with SScPAH $(P=0.03)$ (Figure 2). Moreover, intensity of immunoreactivity in the pooled arterioles and small vessels was weaker in IPAH than in SScPAH $(P=0.02)$ (Figure 3$)$. The interlobular veins and venules were focally, mildly stained, but, again, in lower frequency in IPAH than in SScPAH $(P=0.02)$. Capillaries were PDGFR- $\beta$ positive in eight out of nine IPAH cases. Plexiform lesions, observed in eight out of nine IPAH cases, showed mild PDGFR- $\beta$ positivity: in some cases there was only immunoreactivity of endothelium while in other lesions there was immunoreactivity of endothelial and subendothelial stromal cells, with 
Table 1 General patient characteristics

\begin{tabular}{|c|c|c|c|c|}
\hline & $\begin{array}{l}\text { SScPAH } \\
N=5\end{array}$ & $\begin{array}{l}\text { IPAH } \\
N=9\end{array}$ & $\begin{array}{l}\text { PVOD } \\
N=6\end{array}$ & $\begin{array}{l}\text { Control } \\
N=5\end{array}$ \\
\hline Age, yrs & 51 (32 to 60$)$ & 53 (23 to 59$)$ & 33 (23 to 59$)$ & 33 (24 to 76$)$ \\
\hline Male/Female (n) & $1 / 4$ & $2 / 7$ & $3 / 3$ & $5 / 0$ \\
\hline Antibody (Ab) profile & $\begin{array}{l}\text { anti-centromere: } \\
5(100 \%)\end{array}$ & 0 & 0 & \\
\hline Disease duration of PAH at time of death/biopsy (yrs) & $1(0.1$ to 4.0$)$ & 2.6 (0.8 to 9.0$)$ & $1.9(0.08$ to 5.0$)$ & \\
\hline \multicolumn{5}{|l|}{$\begin{array}{l}\text { Therapy at time of } \\
\text { death/biopsy }\end{array}$} \\
\hline \multicolumn{5}{|l|}{ Monotherapy: } \\
\hline prostacycline & 3 & 6 & 4 & \\
\hline PDE-5 inhibitor & 0 & 1 & 0 & \\
\hline ERA & 0 & 1 & 2 & \\
\hline \multicolumn{5}{|l|}{ Combination therapy: } \\
\hline Prostacycline+ERA+ & & 0 & 0 & \\
\hline PDE-5 inibitor (n) & 1 & & & \\
\hline ERA+PDE-5 inhibitor (n) & 1 & 0 & 0 & \\
\hline ERA+prostacycline (n) & 0 & 1 & 0 & \\
\hline Limited cutaneous SSc, n (\%) & $5(100 \%)$ & & & \\
\hline SSc disease duration, yrs * & $2(1$ to 34$)$ & & & \\
\hline Raynaud phenomenon duration, yrs & 13 (1 to 40 ) & & & \\
\hline
\end{tabular}

Values expressed as median (range) or otherwise as stated. * Since first non-Raynaud symptom, at time of diagnosis of pulmonary arterial hypertension.

ABS, atrial balloon septostomia; ERA, endothelin receptor antagonist; IPAH, idiopathic PAH; PDE-5, phosphodiesterase 5; PVOD, pulmonary veno-occlusive disease; $\mathrm{SSCPAH}$, systemic sclerosis-associated pulmonary arterial hypertension (PAH).

Table 2 Haemodynamic parameters

\begin{tabular}{|c|c|c|c|}
\hline & $\begin{array}{l}\text { SScPAH } \\
N=5\end{array}$ & $\begin{array}{l}\text { IPAH } \\
N=9\end{array}$ & $\begin{array}{l}\text { PVOD } \\
N=6 \\
\end{array}$ \\
\hline $\mathrm{mRpa}, \mathrm{mmHg}$ & $\begin{array}{l}10(6 \text { to } 18) \\
(n=4)\end{array}$ & $\begin{array}{l}11(7 \text { to } 23) \\
(n=5)\end{array}$ & $\begin{array}{l}10(5 \text { to } 15) \\
(n=5)\end{array}$ \\
\hline sPpa, mmHg & $\begin{array}{l}78 \text { (70 to 101) } \\
(n=5)\end{array}$ & $\begin{array}{l}100(62 \text { to } 109) \\
(n=9)\end{array}$ & $\begin{array}{l}76(58 \text { to } 100) \\
(n=6)\end{array}$ \\
\hline $\mathrm{mPpa}, \mathrm{mmHg}$ & $\begin{array}{l}55(43 \text { to } 71) \\
(n=5)\end{array}$ & $\begin{array}{l}55(43 \text { to } 76) \\
(n=7)\end{array}$ & $\begin{array}{l}49(45 \text { to } 70) \\
(n=6)\end{array}$ \\
\hline PCWP, mmHg & $\begin{array}{l}9(5 \text { to } 12) \\
(n=5)\end{array}$ & $\begin{array}{l}7(1 \text { to } 12) \\
(n=7)\end{array}$ & $\begin{array}{l}5(5 \text { to } 11) \\
(n=6)\end{array}$ \\
\hline $\begin{array}{l}\text { PVR, } \\
\text { dynes } s \cdot \mathrm{cm}^{-5}\end{array}$ & $1054(627$ to 3278$)(n=4)$ & 957 (916 to 1587$)(n=6)$ & $750(479$ to 1483$)(n=7)$ \\
\hline $\mathrm{Cl}, \mathrm{l} / \mathrm{min} \cdot \mathrm{m}^{2}$ & $\begin{array}{l}2.2(1.1 \text { to } 2.9) \\
(n=7)\end{array}$ & $\begin{array}{l}2.4(1.3 \text { to } 3.2) \\
(n=8)\end{array}$ & $\begin{array}{l}2.6(1.9 \text { to } 3.1) \\
(n=6)\end{array}$ \\
\hline FEV1, \% & $92(77$ to 97$)(n=4)$ & $\begin{array}{l}80(56 \text { to } 111) \\
(n=8)\end{array}$ & $82(74$ to 95$)(n=6)$ \\
\hline TLC, \% & $\begin{array}{l}87(81 \text { to } 115) \\
(n=3)\end{array}$ & $\begin{array}{l}94 \text { (78 to } 113) \\
(n=9)\end{array}$ & $\begin{array}{l}90(81 \text { to } 105) \\
(n=6)\end{array}$ \\
\hline VC, \% & $\begin{array}{l}99(88 \text { to } 120) \\
(n=4)\end{array}$ & $\begin{array}{l}87 \text { (58 to } 119) \\
(n=8)\end{array}$ & * \\
\hline TLCO, \% & $\begin{array}{l}35 \text { (26 to } 57) \\
(n=4)\end{array}$ & $\begin{array}{l}60(52 \text { to } 90) \\
(n=8)\end{array}$ & $\begin{array}{l}49(20 \text { to } 69) \\
(n=6)\end{array}$ \\
\hline
\end{tabular}

Values expressed as median (range) or otherwise as stated. ${ }^{*}$ not available

$\mathrm{Cl}$, cardiac index; FEV1 \%, percentage predicted of forced expiratory volume; IPAH, idiopathic PAH; mRpa, mean right atrial pressure; PCWP, pulmonary capillary wedge pressure; PVOD, pulmonary veno-occlusive disease; PVR, pulmonary vascular resistance; sPpa, mPpa, systolic, mean pulmonary artery pressures; SScPAH, systemic sclerosis-associated pulmonary arterial hypertension (PAH); TLC \%, percentage of predicted total long capacity; TLCO \%, percentage predicted of transfer factor of the lung for carbon monoxide; VC, percentage predicted of vital capacity. 

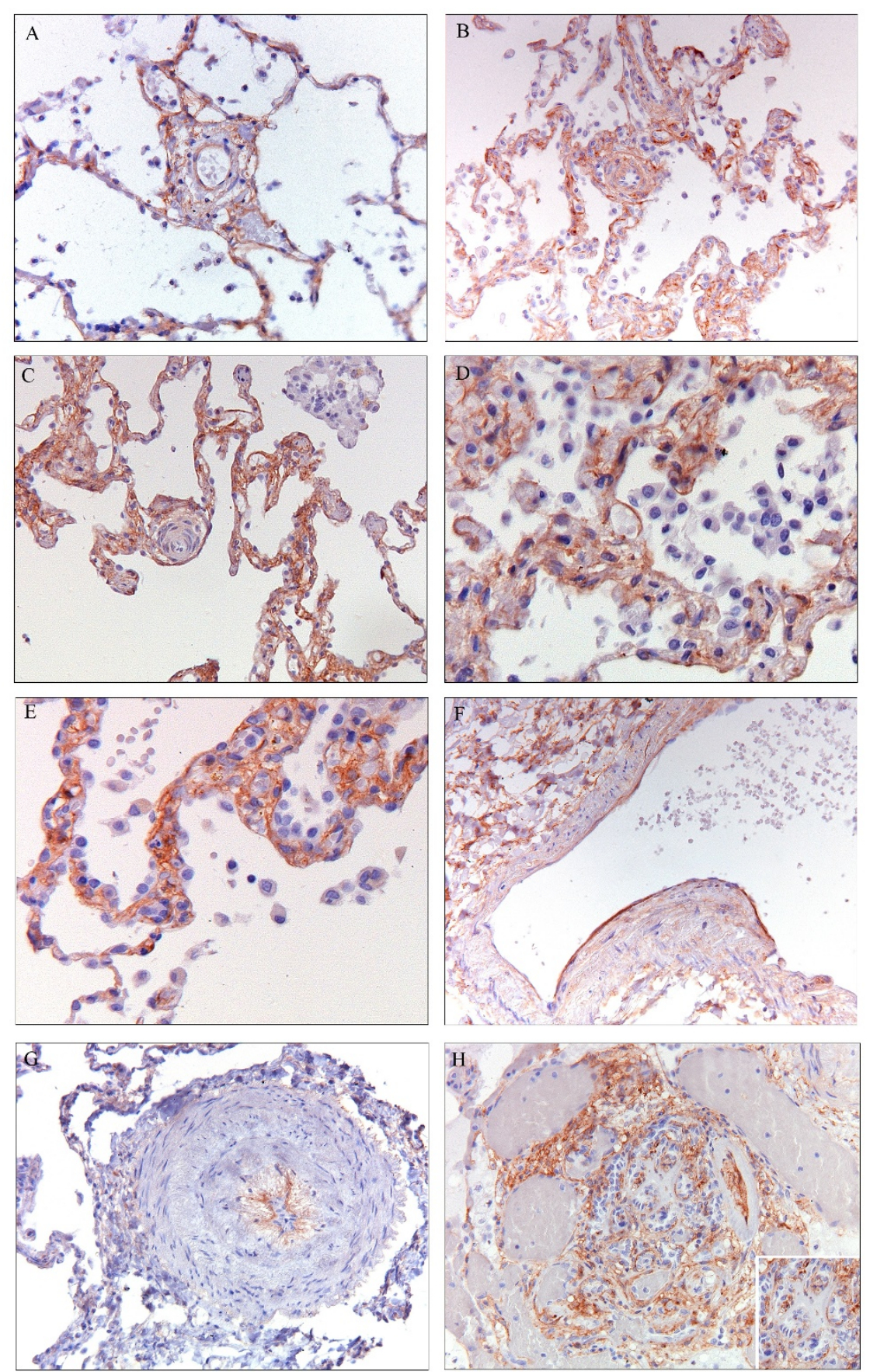

Figure 1 Plateled-derived growth factor receptor (PDGFR)- $\beta$ immunoreactivity in pulmonary vessels in SSCPAH, IPAH and PVOD (Original magnification 200x). A) PDGFR- $\beta$ immunoreactivity in the endothelial layer of a small corner vessel without fibrosis in SScPAH. Note the epithelial immunoreactivity at the alveolar attachments of the corner vessel, serving as an internal positive control. B) PDGFR- $\beta$ immunoreactivity in the endothelium of a small corner vessel with fibrosis in SSCPAH, and in the (congested) capillary endothelium. C) Absence of PDGFR- $\beta$ immunoreactivity in the endothelial layer of a small corner vessel with intimal fibrosis, in an area of capillary congestion, in PVOD. There is epithelial immunoreactivity at the alveolar attachments of the corner vessel. D) PDGFR- $\beta$ immunoreactivity in endothelial cells of capillaries in a SSCPAH patient. E) Intense PDGFR- $\beta$ endothelial immunoreactivity in an area of congestion in a PVOD patient. F) PDGFR- $\beta$ endothelial immunoreactivity in a vein in a SSCPAH patient. G) PDGFR- $\beta$ immunoreactivity in the basal side of the endothelium of an arteriole with intimal fibrosis and media hyperplasia in an IPAH patient. H) PDGFR- $\beta$ immunoreactivity in a plexiform lesion in an IPAH patient;

immunoreactivity of basal side of the endothelial cells (insert) in the glomeruloid lesion, surrounded by vein-like branches (dilatation lesions). 


\section{Prevalence of PDGFR- $\beta$ expression}
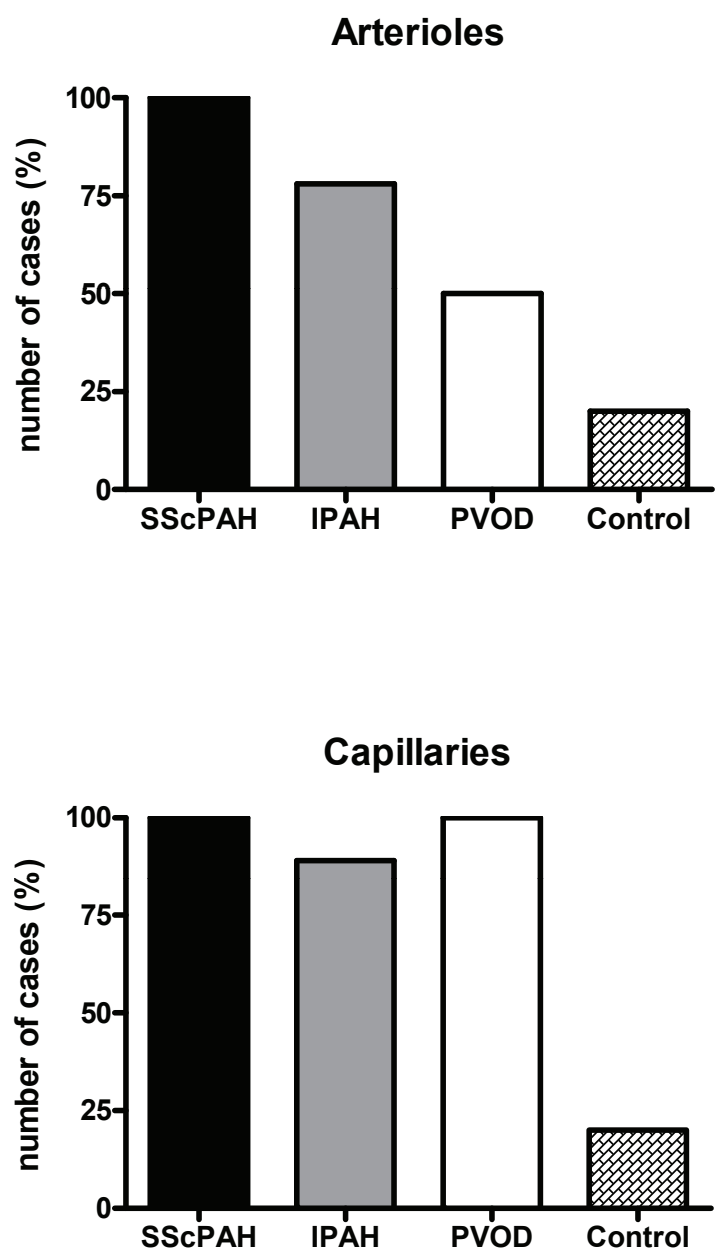

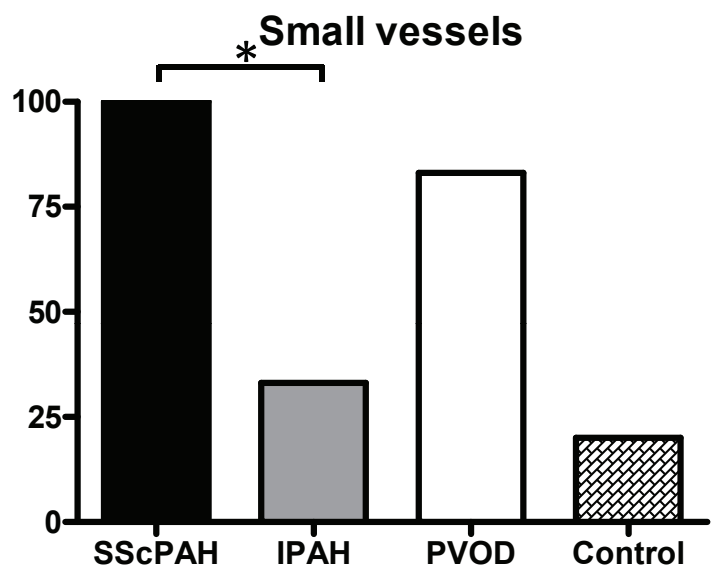

Veins

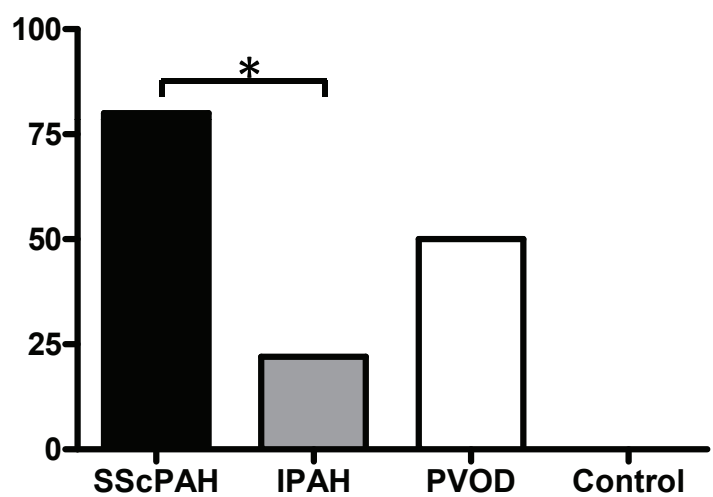

Figure 2 Number of cases with plateled-derived growth factor receptor (PDGFR)- $\beta$-immunoreactivity in the intima of pulmonary vessels in SSCPAH, IPAH, PVOD, controls. Small vessels: those arterioles and/or venules that cannot be distinguished based on their anatomical localisation. ${ }^{*} P<0.05$

thin lines of positive immunoreactivity demarcating the basal side of endothelial cells (Figure $1 \mathrm{H}$ ).

Two out of six PVOD cases demonstrated intimal immunoreactivity in the entire spectrum of the pulmonary vasculature. Pre-capillary intimal and adventitial immunoreactivity with a mild intensity was observed focally in three PVOD patients. In five out of six patients, a focal immunoreactivity of small vasculature intima was observed (Figure 2). Capillary immunoreactivity, present in areas with and without congestion, was widespread (Figure 1E), with an intensity from mild to strong. No differences were found in prevalence, localisation or intensity of PDGFR- $\beta$ in the PVOD group when compared to the SScPAH or the IPAH group.

In the control group, only one subject demonstrated, focally, a mild PDGFR- $\beta$ immunoreactivity in pre-capillary vessels and capillaries, but not in post-capillary vessels. Figures of control slides are added in an online data supplement (Additional file 3).

\section{pPDGFR- $\beta$ immunoreactivity}

pPDGFR- $\beta$ was present in the pre-, post- and capillary pulmonary vasculature in all patient groups. In Figure 4, 


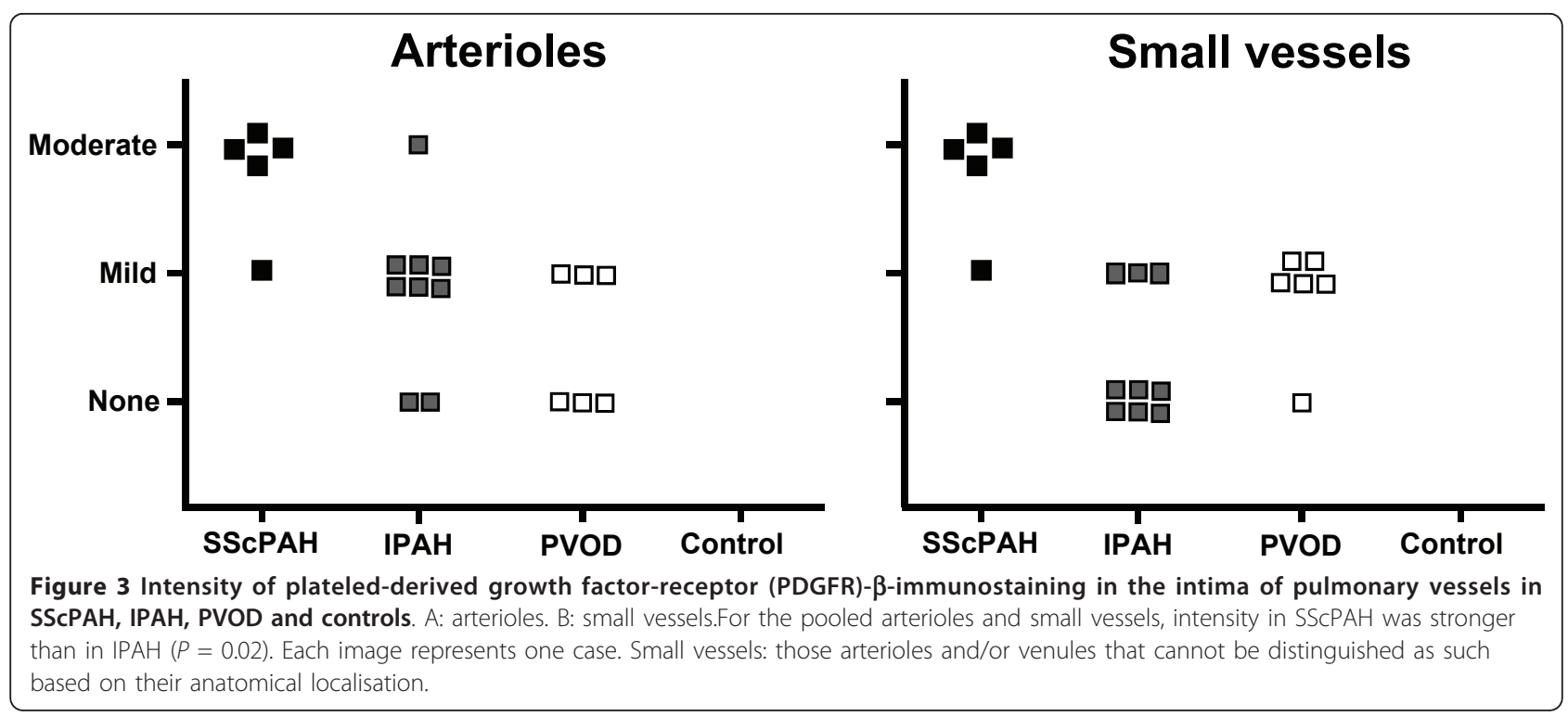

representative pictures of pPDGFR- $\beta$ immunoreactivity are displayed. Staining was predominantly present in the nuclei of the cells. In the pre-capillary vessels, immunoreactivity was observed in the smooth muscle cells of the media in all patient groups. Intimal cells were also positively stained in the diseased groups. This was seen in vessels with and without intimal fibrosis. With a cut off of $25 \%$ cell staining, a trend was shown $(P=0.09)$ in favor of more positive cell immunoreactivity in small vasculature in SScPAH patients vs. IPAH patients

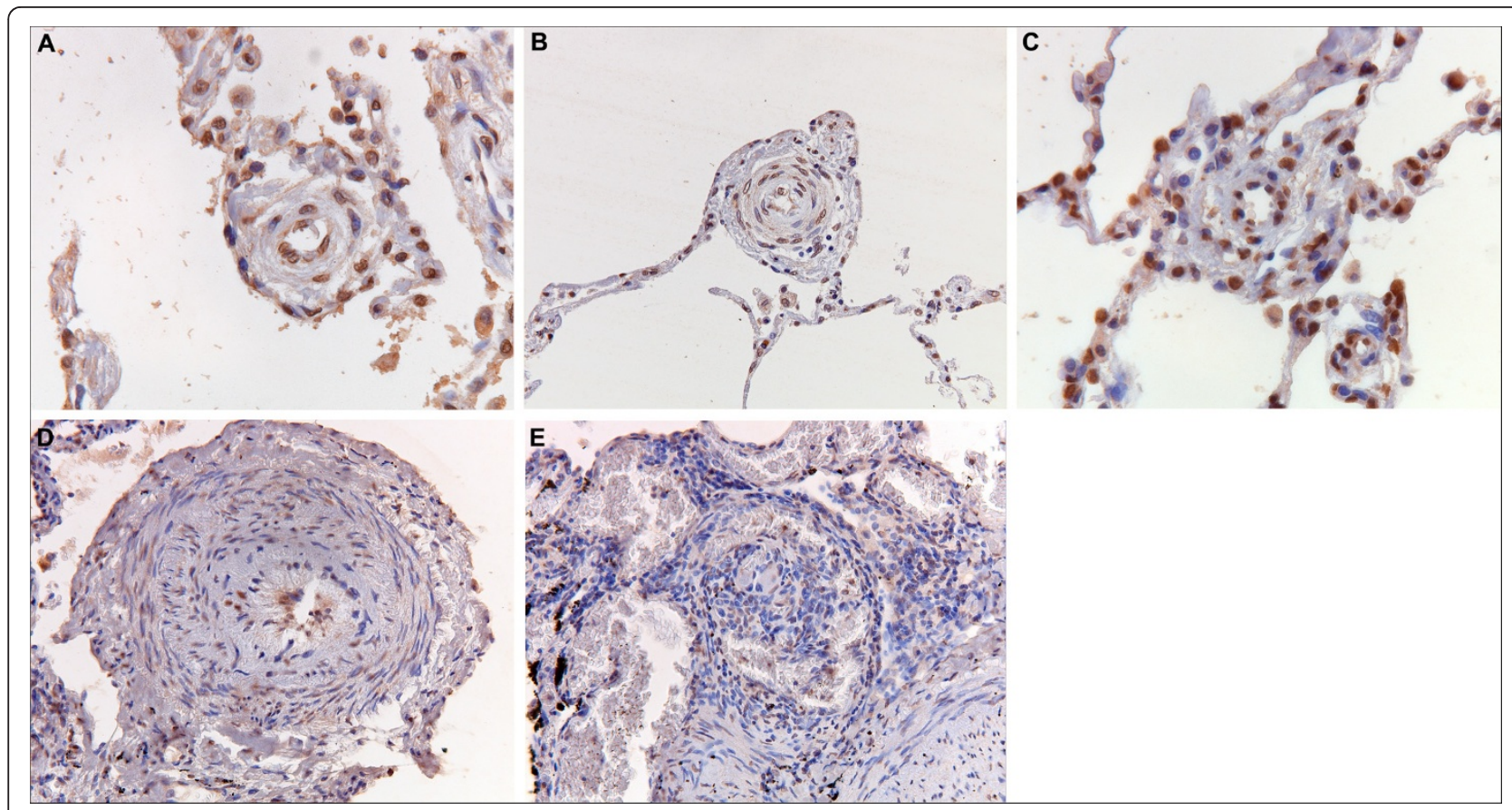

Figure 4 Phosphorylated plateled-derived growth factor receptor (pPDGFR)- $\beta$ immunoreactivity in pulmonary vessels in SScPAH, IPAH and PVOD. (Original magnification 200x) A) PPDGFR- $\beta$ immunoreactivity in endothelial cell nuclei in a small vessel with intimal fibrosis in a patient with SSCPAH. B) pPDGFR- $\beta$ immunoreactivity in cell nuclei in the intima of an arteriole with concentric laminar intimal fibrosis in a patient with SSCPAH (see also 6B). C) pPDGFR- $\beta$ immunoreactivity in cell nuclei of a small vessel and capillaries in a PVOD patient. D) pPDGFR- $\beta$ immunoreactivity in the basal side of the endothelium, the thickened intima and in smooth muscle cells of the hyperplastic media of an arteriole of an IPAH patient (see also Figures 1 G and 6D). E) pPDGFR- $\beta$ immunoreactivity in stroma and endothelium of a plexiform lesion in an IPAH patient. Lower right quadrant parent artery. In the center a glomeruloid lesion surrounded by vein-like branches (dilatation lesions). 
(Figure 5). The capillaries demonstrated immunoreactivity in all patients with no difference between the groups. Post-capillary staining was found in the intimal layers of all SScPAH and PVOD patients and in six out of nine IPAH patients, without quantitative differences. Bronchioles in all patients and controls uniformly demonstrated pPGFR- $\beta$ immunoreactivity in the nuclei of the basal layers of the epithelium and as such served as a positive internal control (Figure 4F). Controls showed staining in the whole pulmonary vascular tree; however, this was a focal staining, with cell counts not exceeding $25 \%$.

\section{PDGF-B immunoreactivity}

PDGF-B demonstrated immunoreactivity in the complete spectrum of the pulmonary vascular tree in all patient groups. Representative pictures of PDFG-B are displayed in Figure 6. One IPAH patient failed to demonstrate immunoreactivity in the capillaries and one PVOD patient did not show PDGF-B staining in the post-capillary vessels. PDGF-B staining was remarkably widespread in the axial arteries and arterioles, both in media and intima. The small vessels demonstrated a widely spread distribution of immunoreactivity. The capillaries were mostly stained in a multifocal to widespread fashion, as were the venules and veins. Staining was more widespread as compared with PDGFR- $\beta$ and PPDGFR- $\beta$, in all patient groups. All the plexiform lesions in the IPAH patients demonstrated immunoreactivity of pPDGFR- $\beta$ and PDGF-B in both the endothelial and stromal cells. As in pPDGFR- $\beta$, PDGF-B was also uniformly positively stained in the observed bronchioles in all subjects, and this yielded a positive internal control.

Controls showed pPDGFR- $\beta$ - and PDGF immunoreactivity in the pulmonary vessels, however, this was a focal, nonuniform staining.

\section{EGFR immunoreactivity}

EGFR was positive in the basal cell layers of the bronchial epithelium, alveolar epithelial cells and type II pneumocytes in all patient and control cases, serving as an internal control. Interestingly, focal areas of positively immunoreactivity type II pneumocytes were found to surround the pre-capillary vessels (Figure 7A, B) in the patient cases and in one control case. No differences in the prevalence of this phenomenon between the patient groups were observed. Capillaries surrounded by EGFRexpressing pneumocytes were observed in all SScPAH patients, in five out of nine IPAH patients and in two out of six PVOD patients.

EGFR immunoreactivity was focal and weak in the pulmonary hypertension groups (Figure 7A-C) and was observed mostly in media and intima of the pulmonary vessels. No differences in immunoreactivity prevalence (Figure 8), intensity or distribution between the pulmonary hypertension groups were observed. Most plexiform lesions demonstrated a weak immunoreactivity of EGFR, which appeared to be located in subendothelial stromal cells (Figure 7D). No immunoreactivity of pulmonary vessels was observed in the control cases.

\section{Discussion}

This study demonstrates the presence of PDGFR-b immunoreactivity in the entire pulmonary vascular bed of SScPAH patients, with a different staining pattern as compared to IPAH. There were no differences in PDGFR- $\beta$ immunoreactivity between SScPAH and PVOD. PDGFR- $\beta$ immunoreactivity was more prevalent and intense in the PAH groups than in controls. There was a trend towards more pPDGFR- $\beta$-positively stained cells in SScPAH small vasculature as compared with

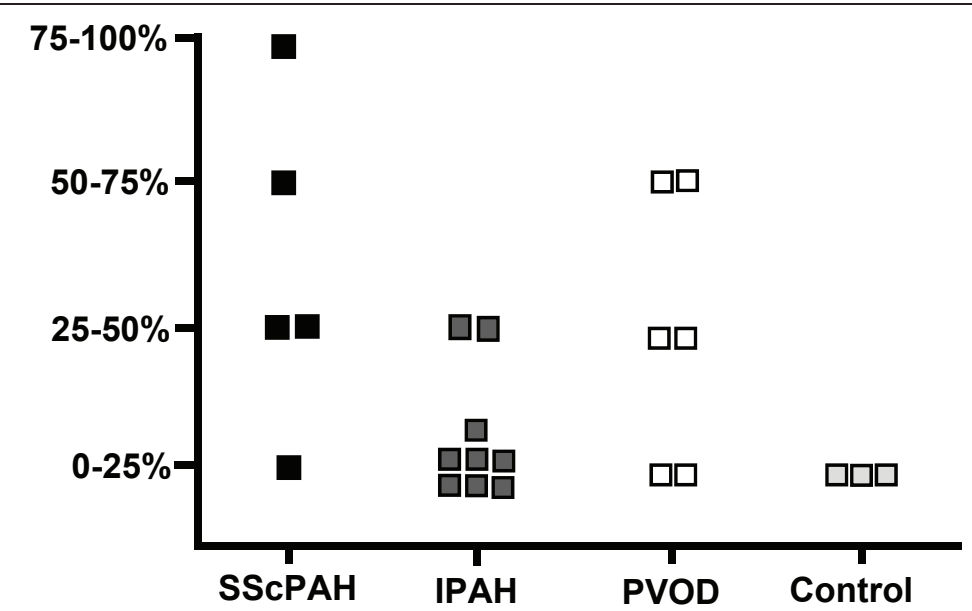

Figure 5 Amount of phosphorylated plateled-derived growth factor receptor (pPDGFR)- $\beta$-positively immunostained cells in intima of the small vessels in SSCPAH, IPAH, PVOD and controls. With a cut off of $25 \%$ cell staining, a trend was shown $(P=0.09)$ in favor of more positive cell immunoreactivity in small vasculature in SScPAH patients vs. IPAH patients. Each image represents one case. 


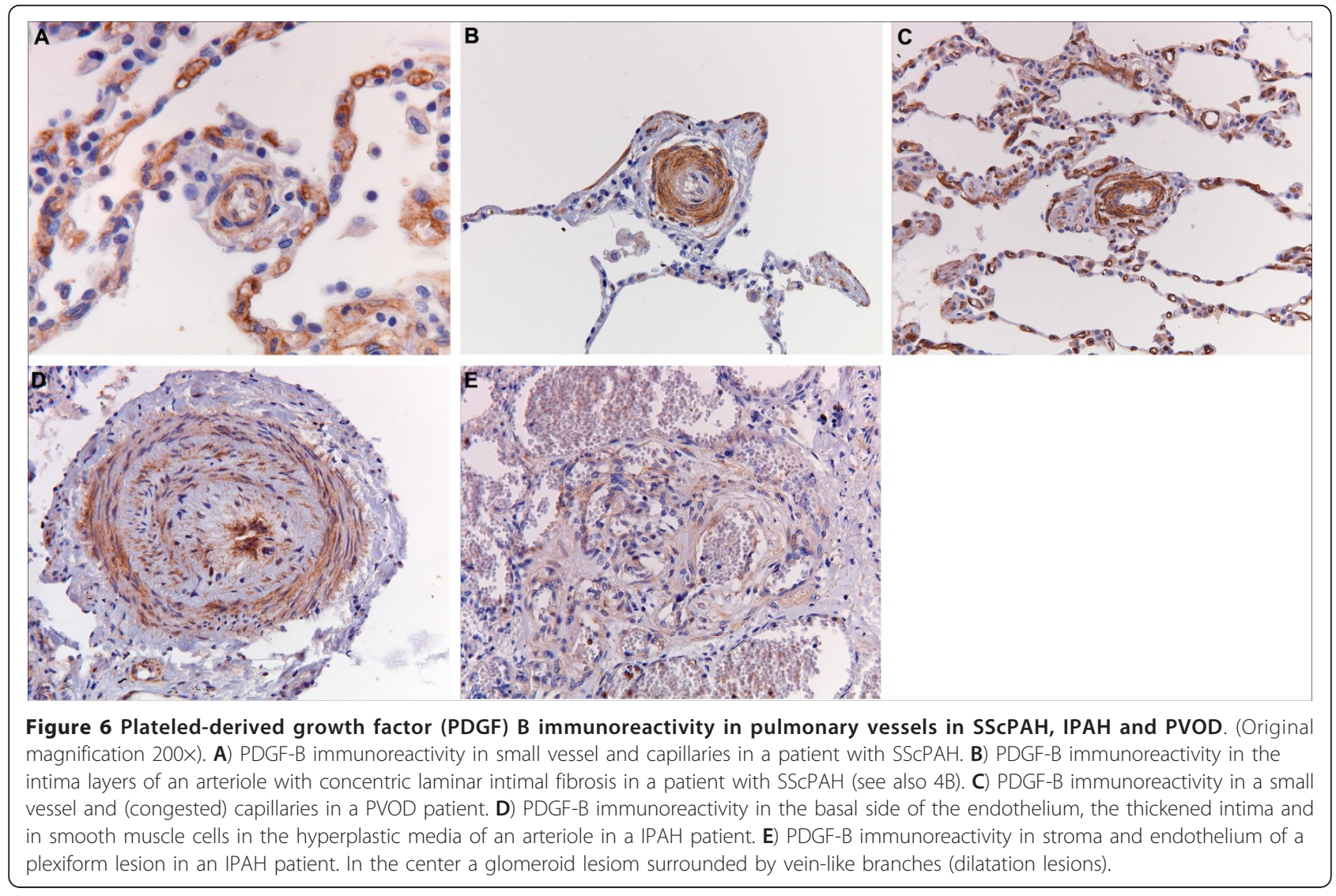

IPAH. EGFR was minimally present in the pulmonary vasculature of SScPAH, IPAH and PVOD, without differences between the groups. No EGFR immunoreactivity was observed in the pulmonary vasculature of controls.

This is the first study to explore PDGFR- $\beta$ - and EGFR immunoreactivity in lung vasculature in SScPAH. PDGFR- $\beta$ is implicated in SSc disease [21-26]. In IPAH, Perros et al. demonstrated PDGFR-b, pPDGFR-b and PDGF-A and -B expression and activity in remodelled small pulmonary arteries and plexiform lesions [33]. In pulmonary capillary haemangiomatosis, an entity that shows overlap with both PVOD [42] and SScPAH [19], up-regulation of PDGF-B and PDGFR- $\beta$ genes has been shown in distended capillaries [43]. The present study supports these findings and extends them by showing the presence of PDGFR- $ß$ immunoreactivity in SScPAH. The different immunoreactivity pattern in the pulmonary vasculature compared to IPAH fits in with the distinctive distribution of vascular lesions in SScPAH. This might implicate a role for PDGFR- $\beta$ in small vessel intimal remodeling in SScPAH.

EGFR expression in human pulmonary vasculature affected by SSc or SScPAH has not been previously reported. We demonstrate EGFR expression, albeit mild and focal, in human pulmonary vasculature of SScPAH, IPAH and PVOD. Dahal et al. [31] failed to show a difference in EGFR expression in lungs of patients with end-stage IPAH and normal controls. This apparent discrepancy compared to the present study may be explained by patient selection, by the use of tissue obtained at lung transplantation and by the evaluation of whole lung tissue by Dahal et al.

The inherent drawback of using archival tissue from different laboratories is shared by other studies. Differences in preparation and in storage time may have an unknown influence on the quantity or quality of immunoreactivity. However, care was taken to limit the influence of age of paraffin blocks, and preparation procedures such as fixation time on epitope availability, by using the constitutive expression of CD31 as a positive control within each case. Moreover, the uniform positive immunoreactivity of bronchiolar epithelium in pPDGFR- $\beta$, PDGF-B and EGFR samples served as an internal positive control.

Antibodies directed at different epitopes than the ones we used for our experiments, might generate different results. This, in combination with differences in antigen blocking steps, might explain why we did not detect PDGFR-b immunoreactivity in the media of pulmonary 

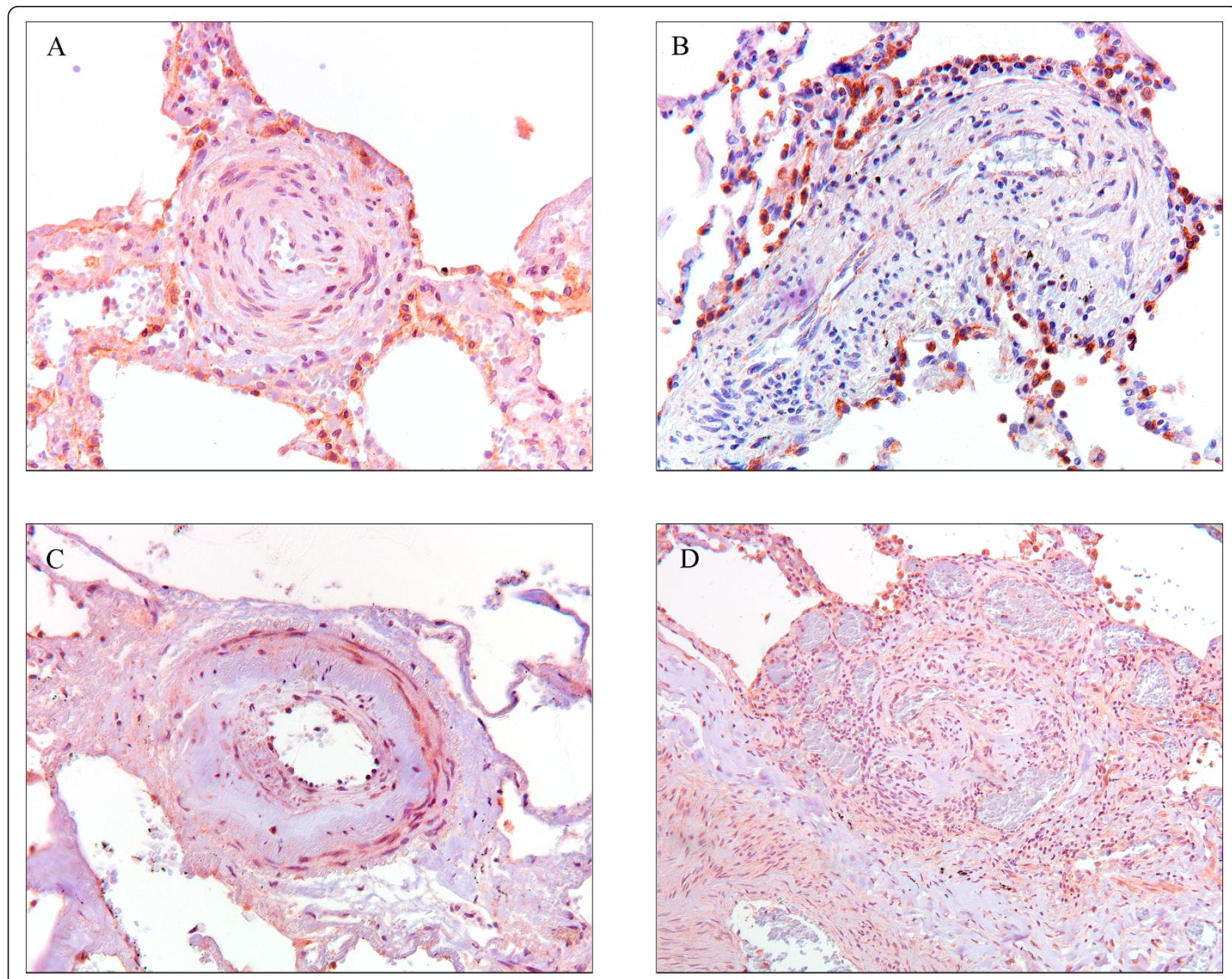

Figure 7 Epidermal growth factor receptor (EGFR) immunoreactivity in pulmonary vessels in SScPAH, IPAH and PVOD. (Original magnification 200x). A) EGFR expression of alveolar epithelium surrounding a parenchymal arteriole (corner vessel) in a SScPAH patient, showing weak immunoreactivity of the media and endothelium. B) Weak EGFR immunoreactivity of endothelial cells in a SSCPAH patient. C) EGFR expression in media and fibrotic intimal layer of an axial artery of a SSCPAH patient. Left lower quadrant: parent artery. Center: glomeruloid lesion, surrounded by dilatation lesions (original magnification 100X). D) Plexiform lesion in an IPAH patient showing weak stromal EFGR expression.

arteries in the IPAH group, in contrast to Perros et al. [33] However, we did demonstrate PDGFR- $\beta$, pPDGFR$\beta$ and PDGF-B immunoreactivity in smooth muscle cells and endothelial cells of constrictive pulmonary arteries and plexiform lesions, which is in concordance with Perros et al. [33] As immunohistochemical immunoreactivity demonstrates the presence but not the activity of (p)PDGFR-b, PDGF-B and EGFR, further studies are needed to further support the rationale for the use of receptor antagonists in SScPAH. The small sample size limits the interpretation of the results. However, only thoroughly characterized unequivocal cases of SScPAH, IPAH and PVOD were included, so as to reduce overlap. As histopathological information on well-characterized SScPAH patients is scarce, the results obtained here provide valuable exploratory information. However, they underscore the need for sampling of suitable tissue specimens in these patient groups for future research, also into receptor functionality studies. The majority of the PVOD samples were biopsies, while the samples from the SScPAH and IPAH group were derived from autopsy material. We cannot exclude some influence on results, as there is no knowledge on post-mortem behaviour of the (p)PDGFR- $\beta$ and PDFG-B. Another influencing factor might be the fact that the biopsy group does not necessarily represent end-stage disease, in contrast to the explanation- and autopsy samples.

How do we interpret these results? The pattern of immunoreactivity of PDGFR- $\beta$ and probably pPDGFR- $\beta$ in SScPAH, IPAH and PVOD follows the distinct 


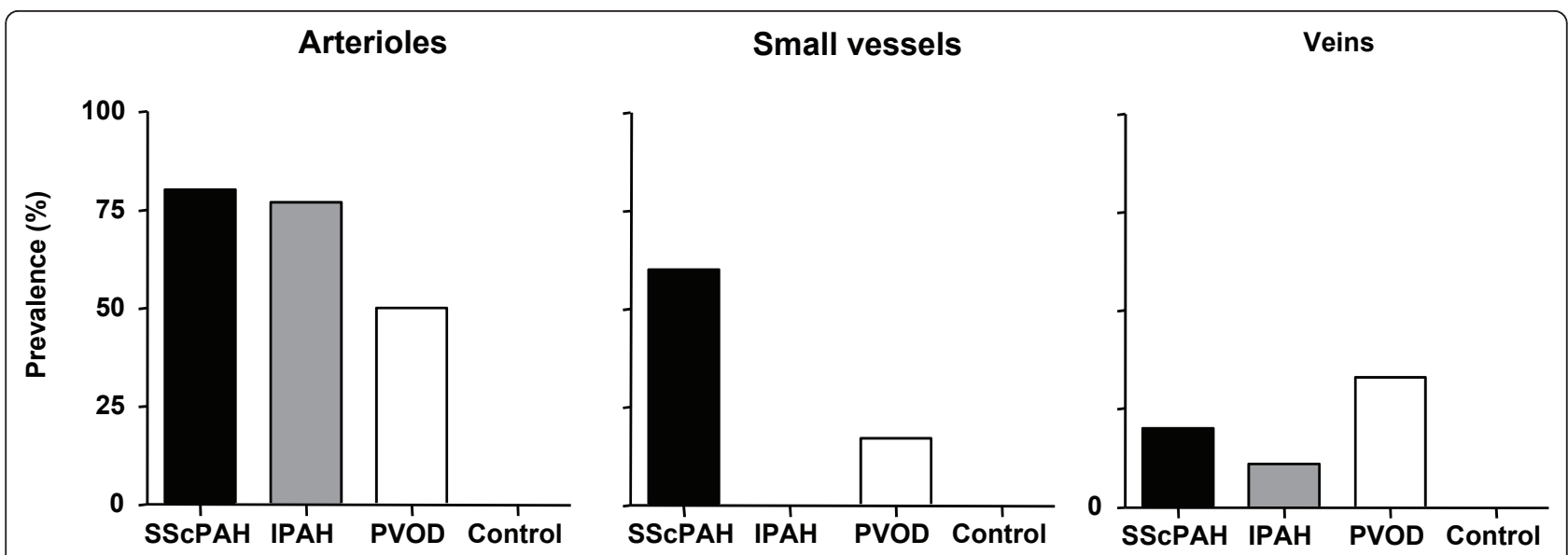

Figure 8 Number of cases with positive immunostaining for epidermal growth factor receptor (EGFR) in the intima of pulmonary vessels. A: arterioles, B: Small vessels, C: veins) in SSCPAH, IPAH, PVOD and normal controls. No staining was observed in the capillaries. Small vessels: those arterioles and/or venules that cannot be distinguished as such by their anatomical localisation

patterns of histomorphologic vasculopathy between these disease groups [20]. The specific role of PDGFR in SScPAH vascular remodeling is further supported by either PDGF or PDGFR autoantibodies [44]. Such antibodies may induce signaling pathways, which eventually may lead to local intimal fibrosis. No differences in the small vessel- and post-capillary vasculature were seen between SScPAH and PVOD. As PVOD-like changes may be seen in SScPAH pulmonary vasculature $[19,20]$ it can be speculated that SScPAH and PVOD share activation of PDGFR-b as a pathophysiologic determinant.

The observation of PDGFR- $\beta$ immunoreactivity, in both affected and non-affected vessels, might be interpreted as pointing towards longstanding pathogenetic involvement. pPDGFR- $\beta$ and PDGF-B showed immunoreactivity in the pulmonary vasculature of the diseased patient group, with an increased prevalence as compared to controls. This supports the pathogenetic role of the PDGFR- $\beta$ pathway in PAH. However, this study neither demonstrated clear parallels in staining patterns between PDGFR- $\beta$ and pPDGFR- $\beta$ nor PDGF$B$ in the SScPAH group. This might be explained by transactivation of PDGFR- $\beta$, resulting in phosphorylation of the PDGFR- $\beta$ [45]. The extent of involvement of the PDGFR- $\beta$ - pPDGFR- $\beta$-signalling pathway in PAH pathogenesis and whether the role of this pathway is different in SScPAH as in IPAH, will need to be investigated in functional studies.

PDGFR- $\beta$ can be inhibited by imatinib, a TKR inhibitor that also has specificity for the Abl-related gene protein in the tyrosine fusion protein Bcr-Abl and c-kit. The effect of imatinib in SSc pathogenesis might be enhanced by its inhibitory effect on c-Abl, which is important for the induction of extracellular matrix components via TGF- $\beta$ signaling $[46,47]$. TGF- $\beta$ is among the most important pro-fibrotic SSc-mediators [67]. This, together with the findings in the present study support the rationale for PDGFR-b targeted therapy in SScPAH. The effects of such therapy might extend to EGFR via transactivation by PDGFR-b, leading to altered signalling of the EGFR [48].

PDGFR- $\beta$, its ligand and its phosphorylated state and EGFR were observed in plexiform lesions of IPAH patients. Their active participation in plexiform lesion formation remains speculative, but Perros et al. [33] demonstrated immunoreactivity of PDGFR- $\beta$, PDGF$\mathrm{BB}$ and phosphorylated PDGFR- $\beta$ in endotheliumlined channels, fitting in with the findings in the present study. This is the first report of EGFR expression in plexiform lesions. It can be speculated that EGFR features in their formation: Tuder et al. demonstrated that endothelial cells in plexiform lesions expressed the transcription factor units HIF-1a and HIF-1b [49]. In cancers, HIF-1 participates in the activation of autocrine signaling pathways involving TGF-a/EGFR and EGF-2/IGF-1R, which promote cell survival and proliferation $[50,51]$. As the role of plexiform lesions in haemodynamic alterations occurring in $\mathrm{PH}$ is unknown, it is uncertain as to whether treatment aimed at their growth factor receptors will be effective in IPAH.

\section{Conclusions}

We demonstrated that the PDGFR-b immunoreactivity pattern in SScPAH differs from that in IPAH, whereas no differences were observed between SScPAH and PVOD. This is in line with differences in distribution and morphologic characteristics of vasculopathy between the disease groups. This might implicate that PDGFR- $\beta$ activation plays a role in pulmonary 
hypertension, which is supported by the presence of its phosphorylated state and the PDGFR-B ligand. The mild immunoreactivity of EGFR in PAH vasculature as compared to its total absence in controls might be an indication of its pathogeneity in $\mathrm{PAH}$, too. This study supports the notion that PDGFR-inhibiting therapy may be effective in the treatment of PAH and of SScPAH in particular, and that multikinase inhibitors deserve consideration as an option in future treatment strategies in pulmonary arterial hypertension.

\section{Additional material}

Additional file 1: Tissue preparation and immunohistochemistry

Additional file concerning detailed description of tissue preparation and immunohistochemistry

Additional file 2: Immunohistochemistry in normal controls.

Additional file with representative figures of immunoreactivity of PDGFR$\beta, p$ PDGFR- $\beta$, PDGF-B and EGFR in normal control subjects. A. PDGFR-b immunoreactivity in a small vessel of a healthy control. B. pPDGFR-b immunoreactivity in a small vessel of a healthy control. C. PDGF AB/BB immunoreactivity in an axial artery and bronchiole of a healthy control. D. EGFR in a small vessel of a healthy control.

Additional file 3: Isoptype-matched control staining additional file with representative figures of isoptype-matched control stainings of SSCPAH-, IPAH- and PVOD-staining

\begin{abstract}
Abbreviations
EGFR: epidermal growth factor receptor; IPAH: idiopathic pulmonary arterial hypertension; PAH: pulmonary arterial hypertension; PDGFR- $\beta$ : plateledderived growth factor receptor- $\beta$; p PDGFR- $\beta$ : phosphorylated plateledderived growth factor receptor- $\beta$; PVOD: pulmonary veno-occlusive disease; SSCPAH: systemic sclerosis-associated pulmonary arterial hypertension.
\end{abstract}

\section{Author details}

'Department of Pulmonary Diseases, VU University Medical Center, De Boelelaan 1117, $1081 \mathrm{HV}$, Amsterdam, The Netherlands. ${ }^{2}$ Department of Rheumatology, VU University Medical Center, De Boelelaan 1117, 1081 HV, Amsterdam, The Netherlands. ${ }^{3}$ Department of Rheumatology, Radboud University Nijmegen Medical Center, Geert-Grooteplein-Zuid 10, 6525 EX, Nijmegen, The Netherlands. ${ }^{4}$ Department of Medical Oncology, VU University Medical Center, De Boelelaan 1117, 1081 HV, Amsterdam, The Netherlands. ${ }^{5}$ Department of Pathology, VU University Medical Center, De Boelelaan 1117, $1081 \mathrm{HV}$, Amsterdam, The Netherlands.

\section{Authors' contributions}

MJO designed the manuscript, collected the patient data and material, performed the immunohistochemistry experiments, scored the immunoreactivity, performed the statistical analysis, analyzed the data and drafted the manuscript. AB and AEV designed the manuscript, analyzed the data and drafted the manuscript. LSH performed immunohistochemistry experiments. MCV collected the patient data and material and analyzed the data. AVN designed the manuscript and drafted the manuscript. WJM analyzed the data and drafted the manuscript. BACD and EFS designed the manuscript and drafted the manuscript. KG designed the manuscript, scored the immunoreactivity, analyzed the data and drafted the manuscript.

\section{Competing interests}

The authors declare that they have no competing interests.

\section{References}

1. Gabrielli A, Avvedimento EV, Krieg T: Scleroderma. N Engl J Med 2009 360:1989-2003.

2. Steen VD, Medsger TA: Changes in causes of death in systemic sclerosis, 1972-2002. Ann Rheum Dis 2007, 66:940-944.

3. Hachulla E, Gressin V, Guillevin L, Carpentier P, Diot E, Sibilia J, Kahan A, Cabane J, Francès C, Launay D, Mouthon L, Allanore Y, Tiev KP, Clerson P, De Groote $P$, Humbert M: Early detection of pulmonary arterial hypertension in systemic sclerosis: a French nationwide prospective multicenter study. Arthritis Rheum 2005, 52:3792-3800.

4. Mukerjee D, St George D, Coleiro B, Knight C, Denton CP, Davar J, Black CM, Coghlan JG: Prevalence and outcome in systemic sclerosis associated pulmonary arterial hypertension: application of a registry approach. Ann Rheum Dis 2003, 62:1088-1093.

5. Condliffe R, Kiely DG, Peacock AJ, Corris PA, Gibbs JS, Vrapi F, Das C, Elliot CA, Johnson M, DeSoyza J, Torpy C, Goldsmith K, Hodgkins D, Hughes RJ, Pepke-Zaba J, Coghlan JG: Connective tissue diseaseassociated pulmonary arterial hypertension in the modern treatment era. Am J Respir Crit Care Med 2009, 179:151-157.

6. Fisher MR, Mathai SC, Champion HC, Girgis RE, Housten-Harris T, Hummers L, Krishnan JA, Wighley F, Hassoun PM: Clinical differences between idiopathic and scleroderma-related pulmonary hypertension. Arthritis Rheum 2006, 54:3043-3050.

7. Hachulla E, Carpentier P, Gressin V, Diot E, Allanore Y, Sibilia J, Launay D, Mouthon L, Jego P, Cabane J, De Groote P, Chabrol A, Lazareth I, Guillevin L, Clerson P, Humbert M, ItinérAIR-Sclérodermie Study Investigators: Risk factors for death and the 3-year survival of patients with systemic sclerosis: the French ItinerAIR-Sclerodermie study. Rheumatology (Oxford) 2009, 48:304-308.

8. Kawut SM, Taichman DB, Archer-Chicko CL, Palevsky HI, Kimmel SE: Hemodynamics and survival in patients with pulmonary arterial hypertension related to systemic sclerosis. Chest 2003, 123:344-350.

9. Girgis RE, Mathai SC, Krishnan JA, Wigley FM, Hassoun PM: Long-term outcome of bosentan treatment in idiopathic pulmonary arterial hypertension and pulmonary arterial hypertension associated with the scleroderma spectrum of diseases. J Heart Lung Transplant 2005, 24:1626-1631.

10. Mathai SC, Girgis RE, Fisher MR, Champion HC, Housten-Harris T, Zaiman A, Hassoun PM: Addition of sildenafil to bosentan monotherapy in pulmonary arterial hypertension. Eur Respir J 2007, 29:469-475.

11. Rubin LJ, Badesch DB, Barst RJ, Galie N, Black CM, Keogh A, Pulodo T, Frost A, Roux S, Leconte I, Landzberg M, Simmoneau G: Bosentan therapy for pulmonary arterial hypertension. N Engl J Med 2002, 346:896-903.

12. Badesch DB, Tapson VF, McGoon MD, Brundage BH, Rubin LJ, Wigley FM, Rich S, Barst RJ, Barrett PS, Kral KM, Jobsis MM, Loyd JE, Murali S, Frost A, Girgis R, Bourge RC, Ralph DD, Elliot CG, Hill NS, Langleben D, Schilz RJ, Mc Laughlin W, Robins IM, Groves BM, Shapirp S, Medsger T Jr: Continuous intravenous epoprostenol for pulmonary hypertension due to the scleroderma spectrum of disease. A randomized, controlled trial. Ann Intern Med 2000, 132:425-434

13. Badesch DB, Hill NS, Burgess G, Rubin LJ, Barst RJ, Simmonneau G: Sildenafil for Pulmonary Arterial Hypertension Associated with Connective Tissue Disease. J Rheumatol 2007, 34:2417-2422.

14. Overbeek MJ, Lankhaar JW, Westerhof N, Voskuyl AE, Boonstra A, Bronzwaer JG, Marques KM, Smit EF, Dijkmans BA, Vonk-Noordegraaf A: Right ventricular contractility in systemic sclerosis-associated and idiopathic pulmonary arterial hypertension. Eur Respir J 2008, 31:1160-1166.

15. Steen $V$, Medsger TA Jr: Predictors of isolated pulmonary hypertension in patients with systemic sclerosis and limited cutaneous involvement. Arthritis Rheum 2003, 48:516-522.

16. Sun XG, Hansen JE, Oudiz RJ, Wasserman K: Pulmonary function in primary pulmonary hypertension. J Am Coll Cardiol 2003, 41:1028-1035.

17. Fisher MR, Mathai SC, Champion HC, Girgis RE, Housten-Harris T, Hummers L, Krishnan JA, Wighley F, Hassoun PM: Clinical differences between idiopathic and scleroderma-related pulmonary hypertension. Arthritis Rheum 2006, 54:3043-3050.

18. Steen $V$, Medsger TA Jr: Predictors of isolated pulmonary hypertension in patients with systemic sclerosis and limited cutaneous involvement. Arthritis Rheum 2003, 48:516-522. 
19. Dorfmuller P, Humbert M, Perros F, Sanchez O, Simonneau G, Muller KM Capron F: Fibrous remodeling of the pulmonary venous system in pulmonary arterial hypertension associated with connective tissue diseases. Hum Pathol 2007, 38:893-902.

20. Overbeek MJ, Vonk MC, Boonstra A, Voskuyl AE, Vonk-Noordegraaf A, Smit EF, Dijkmans BA, Postmus PE, Mooi WJ, Heijdra Y, Grunberg K: Pulmonary arterial hypertension in limited cutaneous systemic sclerosis: a distinctive vasculopathy. Eur Respir J 2009, 34:371-379.

21. Distler JH, Jungel A, Huber LC, Schulze-Horsel U, Zwerina J, Gay RE, Michel BA, Hauser T, Schet G, Gay S, Distler O: Imatinib mesylate reduces production of extracellular matrix and prevents development of experimental dermal fibrosis. Arthritis Rheum 2007, 56:311-322.

22. Gay S, Jones RE Jr, Huang GQ, Gay RE: Immunohistologic demonstration of platelet-derived growth factor (PDGF) and sis-oncogene expression in scleroderma. J Invest Dermatol 1989, 92:301-303.

23. Klareskog L, Gustafsson R, Scheynius A, Hallgren R: Increased expression of platelet-derived growth factor type $B$ receptors in the skin of patients with systemic sclerosis. Arthritis Rheum 1990, 33:1534-1541.

24. Ludwicka A, Ohba T, Trojanowska M, Yamakage A, Strange C, Smith EA, Leroy EC, Sutherland S, Silver RM: Elevated levels of platelet derived growth factor and transforming growth factor-beta 1 in bronchoalveolar lavage fluid from patients with scleroderma. J Rheumatol 1995, 22:1876-1883

25. Pandolfi A, Florita M, Altomare G, Pigatto P, Donati MB, Poggi A: Increased plasma levels of platelet-derived growth factor activity in patients with progressive systemic sclerosis. Proc Soc Exp Biol Med 1989, 191:1-4.

26. Akhmetshina A, Venalis P, Dees C, Busch N, Zwerina J, Schett G: Treatment with imatinib prevents fibrosis in different preclinical models of systemic sclerosis and induces regression of established fibrosis. Arthritis Rheum 2009, 60:219-224

27. Kawamoto T, Nishi M, Takahashi K, Nishiyama T, Sato JD, Taniguchi S: Stimulation by transforming growth factor-beta of epidermal growth factor-dependent growth of aged human fibro-blasts: recovery of high affinity EGE receptors and growth stimulation by EGF. In Vitro Cell Dev Biol 1989, 25:965-970.

28. Tokiyama K, Yokota E, Niho Y: Epidermal growth factor receptor of fibroblasts from patients with scleroderma 1. J Rheumatol 1990, 17:1463-1468.

29. Merklinger SL, Jones PL, Martinez EC, Rabinovitch M: Epidermal growth factor receptor blockade mediates smooth muscle cell apoptosis and improves survival in rats with pulmonary hypertension. Circulation 2005, 112:423-431.

30. Schermuly RT, Dony E, Ghofrani HA, Pullamsetti S, Savai R, Roth M, Sydykov A, Lai YJ, Weissman N, Seeger W, Grimmiger F: Reversal of experimental pulmonary hypertension by PDGF inhibition. J Clin Invest 2005, 115:2811-2821.

31. Dahal BK, Cornitescu T, Tretyn A, Pullamsetti SS, Kosanovic D, Dumitrascu R, Ghofrani HA, Weissmann N, Grimmiger F, Seeger W, Schermuly RT: Role of epidermal growth factor inhibition in experimental pulmonary hypertension. Am J Respir Crit Care Med 2010, 181:158-167.

32. Graves LM, Han J, Earp HS III: Transactivation of the EGF receptor: is the PDGF receptor an unexpected accomplice? Mol Interv 2002, 2:208-212.

33. Perros F, Montani D, Dorfmuller P, Durand-Gasselin I, Tcherakian C, Le Pavec J, Mazmanian M, Fadel E, Mussot S, Mercier O, Herve P, Emilie D, Eddahibi S, Simmonneau G, Souza R, Humbert M: Platelet-derived growth factor expression and function in idiopathic pulmonary arterial hypertension. Am J Respir Crit Care Med 2008, 178:81-88.

34. Ghofrani HA, Seeger W, Grimminger F: Imatinib for the treatment of pulmonary arterial hypertension. N Engl J Med 2005, 353:1412-1413.

35. Overbeek MJ, Nieuw Amerongen GP, Boonstra A, Smit EF, VonkNoordegraaf A: Possible role of imatinib in clinical pulmonary venoocclusive disease. Eur Respir J 2008, 32:232-235.

36. Patterson KC, Weissmann A, Ahmadi T, Farber HW: Imatinib mesylate in the treatment of refractory idiopathic pulmonary arterial hypertension. Ann Intern Med 2006, 145:152-153.

37. Souza R, Sitbon O, Parent F, Simonneau G, Humbert M: Long term imatinib treatment in pulmonary arterial hypertension. Thorax 2006, 61:736.

38. Preliminary criteria for the classification of systemic sclerosis (scleroderma). Subcommittee for Scleroderma Criteria of the American Rheumatism Association Diagnostic and Therapeutic Criteria Committee. Arthritis Rheum 1980, 23:581-590.
39. Leroy EC, Black C, Fleischmajer R, Jablonska S, Krieg T, Medsger TA Jr, Rowell N, Wollheim F: Scleroderma (systemic sclerosis): classification, subsets and pathogenesis. J Rheumatol 1988, 15:202-205.

40. Pietra GG, Capron F, Stewart S, Leone O, Humbert M, Robbins IM, Reid LM, Tuder RM: Pathologic assessment of vasculopathies in pulmonary hypertension. J Am Coll Cardiol 2004, 43:25S-32S.

41. Wagenvoort CA, Wagenvoort N: The pathology of pulmonary venoocclusive disease. Virchows Arch A Pathol Anat Histol 1974, 364:69-79.

42. Lantuejoul S, Sheppard MN, Corrin B, Burke MM, Nicholson AG: Pulmonary veno-occlusive disease and pulmonary capillary hemangiomatosis: a clinicopathologic study of 35 cases. Am J Surg Pathol 2006, 30:850-857.

43. Assaad AM, Kawut SM, Arcasoy SM, Rosenzweig EB, Wilt JS, Sonett JR, Borczuk AC: Platelet-derived growth factor is increased in pulmonary capillary hemangiomatosis. Chest 2007, 131:850-855.

44. Baroni SS, Santillo M, Bevilacqua F, Luchetti M, Spadoni T, Mancini M, Fraticelli P, Sambo P, Funaro A, Kazlauskas A, Awedimento EV, Gabrielli A: Stimulatory autoantibodies to the PDGF receptor in systemic sclerosis. N Engl J Med 2006, 354:2667-2676.

45. Chi SS, Vetiska SM, Gill RS, Hsiung MS, Liu F, Van Tol HH: Transactivation of PDGFRbeta by dopamine D4 receptor does not require PDGFRbeta dimerization. Mol Brain 2010, 3:22.

46. Daniels CE, Wilkes MC, Edens M, Kottom TJ, Murphy SJ, Limper AH, Leof EB: Imatinib mesylate inhibits the profibrogenic activity of TGF-beta and prevents bleomycin-mediated lung fibrosis. J Clin Invest 2004, 114:1308-1316.

47. Wang S, Wilkes MC, Leof EB, Hirschberg R: Imatinib mesylate blocks a non-Smad TGF-beta pathway and reduces renal fibrogenesis in vivo. FASEB J 2005, 19:1-11.

48. Varga J, Abraham D: Systemic sclerosis: a prototypic multisystem fibrotic disorder. J Clin Invest 2007, 117:557-567.

49. Tuder RM, Chacon M, Alger L, Wang J, Taraseviciene-Stewart L, Kasahara Y, Cool CD, Bishop AE, Geraci M, Semenza GL, Yacoub M, Polak JM, Voelkel NF: Expression of angiogenesis-related molecules in plexiform lesions in severe pulmonary hypertension: evidence for a process of disordered angiogenesis. J Pathol 2001, 195:367-374.

50. Bos R, van Diest PJ, de Jong JS, van der Groep $P$, van der Valk $P$, van der Wall E: Hypoxia-inducible factor-1alpha is associated with angiogenesis, and expression of bFGF, PDGF-BB, and EGFR in invasive breast cancer. Histopathology 2005, 46:31-36.

51. Tanaka H, Yamamoto M, Hashimoto N, Miyakoshi M, Tamakawa S, Yoshie M, Tokusashi Y, Yokoyama K, Yaginuma Y, Ogawa K: Hypoxia-independent overexpression of hypoxia-inducible factor 1alpha as an early change in mouse hepatocarcinogenesis. Cancer Res 2006, 66:11263-11270.

doi:10.1186/ar3315

Cite this article as: Overbeek et al:: Platelet-derived growth factor receptor- $\beta$ and epidermal growth factor receptor in pulmonary vasculature of systemic sclerosis-associated pulmonary arterial hypertension versus idiopathic pulmonary arterial hypertension and pulmonary veno-occlusive disease: a case-control study. Arthritis Research \& Therapy 2011 13:R61.

\section{Submit your next manuscript to BioMed Central and take full advantage of:}

- Convenient online submission

- Thorough peer review

- No space constraints or color figure charges

- Immediate publication on acceptance

- Inclusion in PubMed, CAS, Scopus and Google Scholar

- Research which is freely available for redistribution

Submit your manuscript at www.biomedcentral.com/submit
C Biomed Central 